\title{
THEORETICAL ASPECTS OF TOURISM ATTRACTIVENESS AND ITS ESTIMATION BY THE EXAMPLE OF THE REPUBLIC OF TATARSTAN
}

Gulnara Faridovna Valeeva

Kazan Federal University Institute of Management, Economics and Finance,

Kazan, Russia

Oleg Aleksandrovich Bunakov

Kazan Federal University Institute of Management, Economics and Finance,

Kazan, Russia

Boris Moishevich Eidelman

Kazan Federal University Institute of Management, Economics and Finance,

Kazan, Russia

Liliya Raisovna Fakhrutdinova

Kazan Federal University Institute of Management, Economics and Finance,

Kazan, Russia

E-mail: gfvaleeva@gmail.com

Recepción: 05/08/2019 Aceptación: 20/09/2019 Publicación: 23/10/2019

Gitación sugerida:

Valeeva, G.F., Bunakov, O.A., Eidelman, B.M. y Fakhrutdinova, L.R. (2019). Theoretical aspects of tourism attractiveness and its estimation by the example of the Republic of Tatarstan. 3C TIC. Cuadernos de desarrollo aplicados a las TIC. Edición Especial, Octubre 2019, 360-373. doi: https://doi.org/10.17993/3ctic.2019.83-2.360-373

Suggested citation:

Valeeva, G.F., Bunakov, O.A., Eidelman, B.M. \& Fakhrutdinova, L.R. (2019). Theoretical aspects of tourism attractiveness and its estimation by the example of the Republic of Tatarstan. 3C TIC. Cuadernos de desarrollo aplicados a las TIC. Special Issue, October 2019, 360-373. doi: https://doi.org/10.17993/3ctic.2019.83-2.360-373 


\section{ABSTRACT}

The article presents the analysis of theoretical approaches to the study of a tourism attractiveness of the region and its elements. Tourism attractiveness of the region is defined as a multi-layered concept reflecting the totality of the subjective and objective characteristics of the region that influence the results of tourist activities and determine the position of the region for the subjects of tourist activities. Presently, the tourism industry is one of the most significant sectors in the development of the region: being aware of it, the state promotes the formation and development of tourism and provides a supportive environment for its development, thereby ensuring the implementation of socially-oriented functions. The management practice of developing the tourism attractiveness of Russian regions should take account of the commercial interests of various business areas, the priorities of state policy and the cultural needs of society. In order to strengthen the tourism appeal, the regions include the development of a set of various actions into the agenda, one of the keys is to form a positive attitude towards the territory and its recognition - regional branding. The Republic of Tatarstan is one of the most promising tourist centers of Russia which actively develops the tourism sector and increases its quantitative indicators and implements large-scale and ambitious projects that improve the tourist attraction.

\section{KEYWORDS}

Tourism, Tourism attractiveness, Region, Regional development, Branding. 


\section{INTRODUCTION}

Today, tourism industry as a highly remunerative and fastest growing economic realm takes on greater and greater importance in the development of individual regions, contributing to the preservation of social and cultural potential and authentic values, natural landscapes and ecosystems of various territories. Being a relatively independent industry, the tourism industry provides a deep integration of social relation and social mobility. Currently in Russia, the tourism industry is at the stage of institutional formation and structural modernization of the tourism infrastructure, the formation of a stable basis for inter-sectoral interaction.

\section{METHODOLOGY}

The methodological framework of the research is represented by a systematic approach to the study of tourism appeal, its elements in their interconnection and interdependence, the method of analysis and synthesis of legal and scientific literature, statistical data.

\section{RESULTS AND DISCUSSION}

The treatment of the essence of the concept "tourism appeal of the regions" should be explored by a multi-stage approach, which includes the study of the following concepts: "tourism", "tourism attractiveness" and "tourism attractiveness of the region".

Exploring the concept of "tourism", we can single out the basic definitions that most fully describe this field of activity.

Buzulukova considers tourism as a temporary movement of people in their free time for recreation, health-improving, educational or business purposes but if they have no work to be paid. 
Glagoleva outlines the definition briefly, thereby revealing the basic essence of the concept, that is, tourism is the departure of a consumer of travel services, not related to extraction of profit.

Kabirov (2016) treats tourism as a set of relationships and services that are associated with a voluntary and temporary change of residence by a traveler for non-professional or non-commercial reasons.

Motyshina in her writings speaks of the essence of tourism more broadly, arguing that it is an economic system with various links between individual elements within the framework of tourist activities.

Rozanova in her writings points to a spiritual part of the tourist sphere, considering tourism as a method of cognition by society of the natural resources and cultural wealth created by nature and humanity.

Sukhanova interprets tourism as a rather complex and multifaceted phenomenon, including social practice, leisure, a special form of consumption, a major cultural phenomenon.

Making a summary of these terms, the concept of "tourism" can be defined as a complex and multifaceted phenomenon, which encapsulates a variety of social relations arising between a large number of subjects and objects in the field of tourism, the consumers of which are the individuals who temporarily change their place of residence in order to have a rest.

The study of the concept of tourism appeal is based on the analysis of the following definitions:

Kalashnikova \& Khanakhok (2015) define tourism attractiveness as a complex activity reflecting travel package, potential, destination culture, tourist place and other industry indicators.

Neterin (2018) considers tourism attractiveness through the lens of the relationship between possible and existing elements and tourist demand. 
As a result, it is possible to put these concepts together and formulate a comprehensive definition of tourism attractiveness as one based on the analysis of the presence of a possible adequate tourism offer, the ability of an object of the sphere of tourism to attract positive attention, to generate interest and repeated demand:

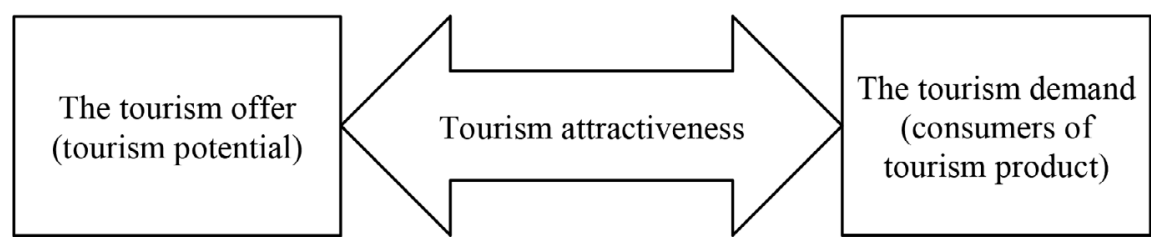

Figure 1. The Essence of the Concept "Tourism Attractiveness".

The concept of tourism attractiveness is considered by many authors in the context of territories, therefore, it is further expedient to explore the essence of the concept of region's tourism appeal.

Likhanina in her works considers tourism attractiveness in relation to the territorial aspect, claiming that it is an element of the competitiveness of the region, its brand and investment potential.

Bunakov (2016) forms the concept of tourism attractiveness of the territory through estimating by potential tourists the ability of the region to meet their needs for recreational, medical and health, professional and business, educational, physical culture and sports, religious and other purposes.

Cheberko interprets tourism appeal of the territory as a combination of various factors that contribute to its high competitiveness in the struggle of tourists of various target groups.

Thus, the tourism attractiveness of the region is a multidimensional concept that reflects the totality of its subjective and objective characteristics affecting the results of tourist activities, and subsequently determining the position of the region for various subjects of touristic activities (considering the resource and infrastructure potential, as well as social institutional risks). 
The role and relationship of tourism attractiveness of the region with elements of regional development is presented schematically in Figure 2:

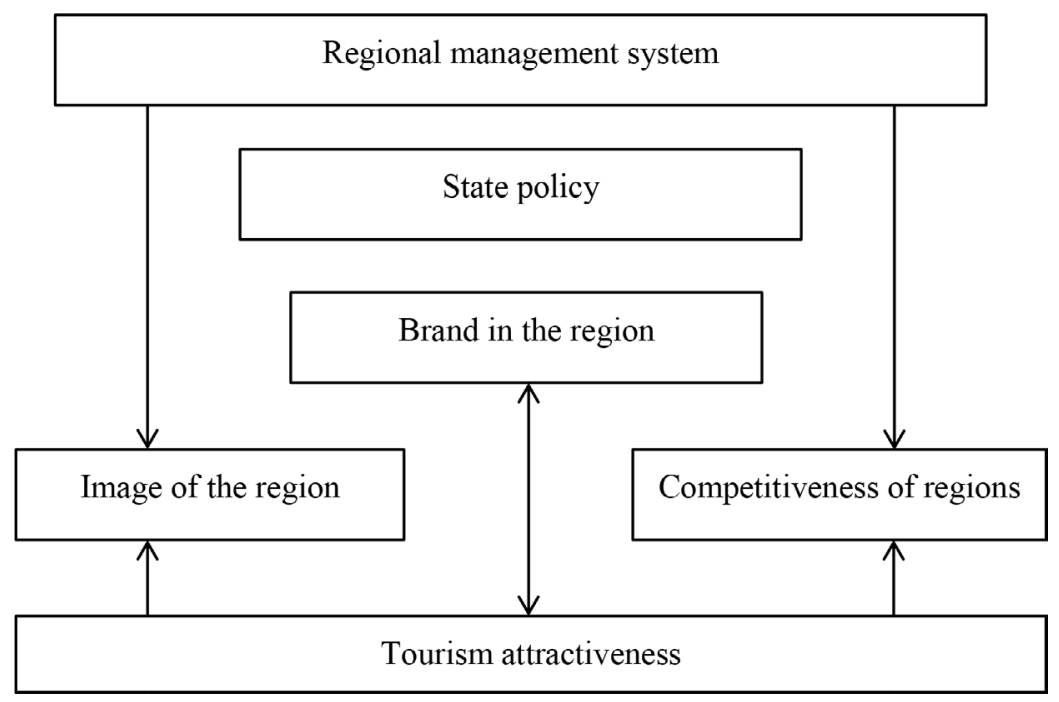

Figure 2. Tourism Attractiveness in Regional Management System. Source: (Tsurtsilina, 2016).

Being a subject of management, the state should recognize the tourism industry as one of the leading sectors of regional development, promote the formation of tourism throughout the territory and create the mechanisms for its effective development.

The formation and development of the tourism appeal of the region is the activity of management entities concerning the determination, generation and achievement of certain objectives and indicators that influence the results of the tourism industry and estimate the rating of the region for the subjects of tourism activity.

Today, in order to develop tourism, any territory includes the elaboration of various activities to the development plan, of which the formation of a positive attitude towards the territory and its recognition - regional branding - grows in popularity. Positioning a positive image of the territory, which is based on the uniqueness of the tourist object, becomes the actual principle of the formation and development of the branded tourist territory (Eidelman et al., 2018). 
The purpose of managing the development of tourism attractiveness of the territory is the formation, generation and development of territorial branding, which is revealed in the formation of competitive or special advantages of a particular region over other regions, as well as the improvement of its image as a tourist destination. The main task in managing the development of tourism appeal of the territory is the creation of such conditions that will attract potential consumers of travel services by increasing in the tourist flow in general.

Strengthening the tourism appeal of the Russian regions includes the areas on which the mechanisms of influence of management practices are oriented, both from the state and regional commercial enterprises. Let us represent the main types of development factors for management practices of improving on Russian regions' image as a tourist destination:

- Creation of tourism image;

- Development of sports, event, conference and business tourism;

- Expansion of recreational potential;

- Development of accommodation business;

- Improvement of tourist-excursion service and transport service;

- Innovations in the field of entertainment.

Currently, in Russia there is a state project "The Strategy for the Development of Tourism in the Russian Federation for the Period up to 2020", which is a driver in the development of territories and the link between the three parties concerned:

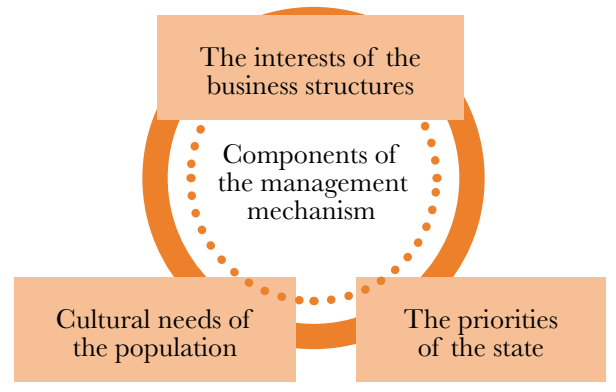

Figure 3. Interrelated Parties in the Management Practice of Strengthening the Tourism Attractiveness of the Russian Regions. 
The management practice of strengthening the tourism appeal of the Russian regions should consider the commercial interests of various business structures, the priorities of the state policy and cultural needs of the society.

The Republic of Tatarstan is one of the most vibrant regions of the Russian Federation in relation to economics and tourism. In terms of gross regional product, the Republic of Tatarstan ranks 6th among the regions of Russia (in 2018 it amounted to 2115.5 billion rubles, or $102.8 \%$ in comparable prices to the level of 2017). The main contribution to economic growth was made by industrial production, agriculture and trade.

The share of the tourism industry in the total structure of the gross regional product of the Republic of Tatarstan for 2018 was $6.1 \%$, the value of the share of the tourism industry for the previous periods did not significantly change (Berdnikova \& Ivanov, 2015).

The tourism attractiveness of the Republic of Tatarstan is constantly strengthened, for example, for a number of previous years large-scale and ambitious projects that contributed to attracting the flow of tourists to the region has been implemented.

Firstly, these are the projects and programs for the revival and preservation of historical and cultural heritage in order to develop tourism and pilgrimage (the city of Bolgar and the island city of Sviyazhsk, holding the 1000th anniversary of Kazan in 2005 and the city of Yelabuga in 2007). Historical sights were also restored, new objects of culture and infrastructure were built. Kazan hosted such major events as the 27th World Summer Universiade in 2013, the World Aquatics Championship in 2015, the Confederation Cup in 2017, the World Football Championship in 2018. New tourist routes and destinations have been opened which are successfully developing and are associated with rural environmental, sports and event, gastronomic, medical, ethnographic and halal tourisms (Eidelman et al., 2018; Niyaz et al., 2018; Bunakov \& Rubtzov, 2016). 
Secondly, these are the programs aimed at creating an innovation infrastructure within the framework of developing business (industrial) tourism. It is worth noting the construction of Russia's largest special economic zone "Alabuga" in 2006, the creation of the city of Innopolis in 2015, the construction of the international investment Technopolis "SMART City Kazan".

Today, the Republic of Tatarstan is one of the most promising tourist centers of Russia. Tourist flow to the republic increases on average by $8 \%$ per year, and by 2019, an increase up to 2 million 450 thousand people is predicted. The income of collective accommodation facilities from the rendered services in 2018 amounted to 8.7 billion rubles, which is $31.5 \%$ more than in the same period of 2017. According to the results of the rating of Russian regions for the growth of income of hotels and similar accommodation facilities over the past 10 years, the rating of Tatarstan has risen from the 12th place to the 4th one. The number of foreign citizens arriving in the republic has increased by $24.3 \%$, compared to 2017:

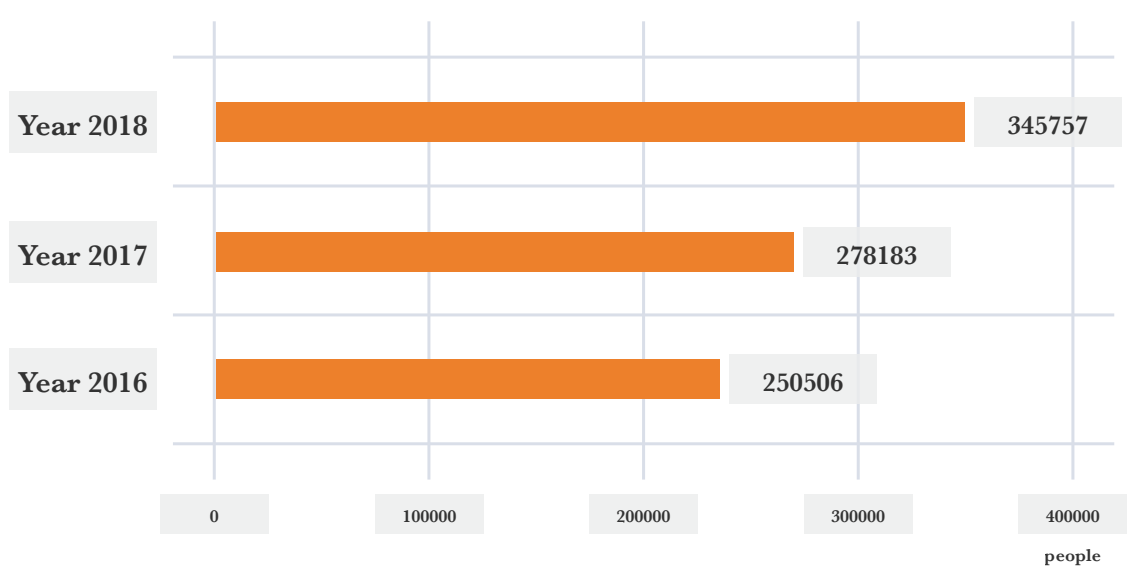

Figure 4. The Number of Foreign Citizens Who Arrived in the Republic of Tatarstan in 2016-2018.

The dynamics of the number of guests of the Republic of Tatarstan who were placed in collective accommodation facilities is presented in the table: 
Table 1. The Dynamics of the Number of Persons Placed in Collective Accommodation Facilities Showing the Target Groups, Thousand People.

\begin{tabular}{|c|c|c|c|c|c|c|}
\hline Name & $\begin{array}{l}\text { Year } \\
2014\end{array}$ & $\begin{array}{l}\text { Year } \\
2015\end{array}$ & $\begin{array}{l}\text { Year } \\
2016\end{array}$ & $\begin{array}{l}\text { Year } \\
2017\end{array}$ & $\begin{array}{l}\text { Year } \\
2018\end{array}$ & $\begin{array}{l}\text { Change in } \\
2018 \text { to } \\
2014 ., \%\end{array}$ \\
\hline $\begin{array}{l}\text { Number of persons served } \\
\text { by collective accommodation } \\
\text { facilities, including }\end{array}$ & 1759,1 & 1782,4 & 1861,2 & 2096 & 2311,1 & 131,4 \\
\hline $\begin{array}{l}\text {-for business, educational and } \\
\text { professional purposes }\end{array}$ & 557,4 & 533,4 & 653,6 & 765,3 & 851,6 & 152,8 \\
\hline $\begin{array}{l}\text { - for the purpose of leisure, } \\
\text { recreation, vacation }\end{array}$ & 733,7 & 855,2 & 947,4 & 1096,6 & 1206,2 & 164,4 \\
\hline - for treatment and prevention & 140,3 & 136,6 & 153,7 & 151,3 & 162,7 & 116,0 \\
\hline - etc. & 327,7 & 227,2 & 106,5 & 82,8 & 90,6 & 27,6 \\
\hline
\end{tabular}

Most tourists visit the republic for the purpose of leisure activity, recreation, vacation, as well as for business reasons. In 2018, the number of guests who visited the Republic of Tatarstan for tourism purposes amounted to 2,311.1 thousand people, which is $131.4 \%$ more than in 2014 .

The structure of the tourists of the Republic of Tatarstan according to the purpose of the trip for 2018 is presented in Figure 5:

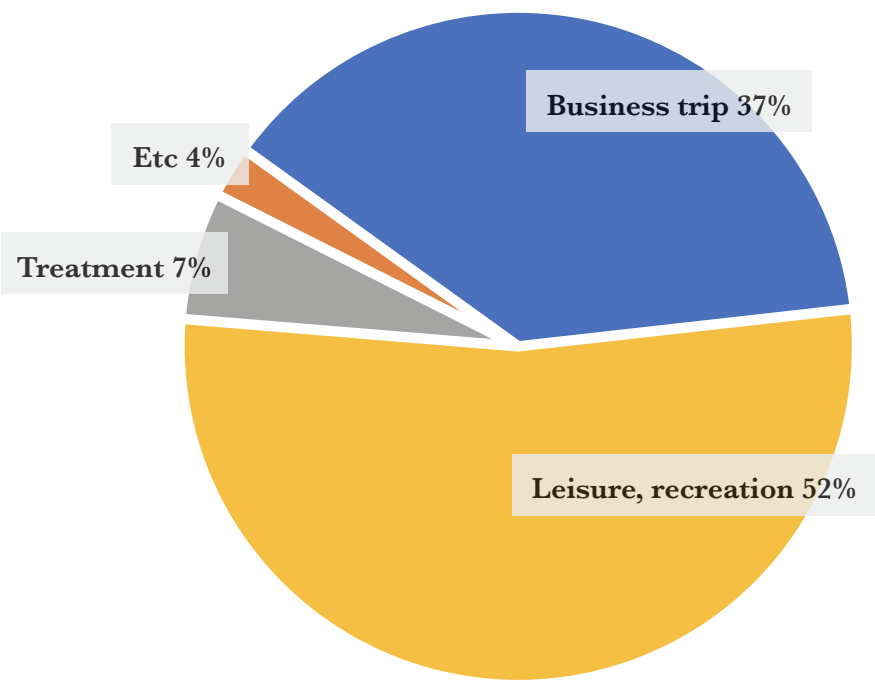

Figure 5. The Structure of Tourists of the Republic of Tatarstan According to the Purpose of the Trip for 2018. 


\section{SUMMARY}

The tourism potential of the Republic of Tatarstan characterized by a combination of great history and rich culture of the East and West, Islam and Orthodoxy, a good geographical location and national distinctive features should be focused on the development of all areas of tourism that can give a significant economic effect. Maintaining and increasing the pace of tourism development in the Republic of Tatarstan today is the most important strategic task of all participants of the tourism market, as the tourism brand of Tatarstan contributes to strengthening competitive positions, attracting investors, expanding the network of travel business and developing the entire tourist industry on the whole.

\section{CONCLUSIONS}

The issues of tourism draw of the regions today are an important aspect of regional development, this is due to its influence on regional socio-economic development, one of the key indicators of which is the gross regional product. The Republic of Tatarstan is one of the most effective and successful regions of Russia in the formation and development of travel industry. Being an economically prosperous region, Tatarstan is constantly enhancing its competitive advantages in the tourism industry by holding large-scale events on forming tourist loyalty, building new demonstration facilities, places and destinations that help attract tourist flows.

\section{ACKNOWLEDGEMENTS}

The work is performed according to the Russian Government Program of Competitive Growth of Kazan Federal University. 


\section{REFERENCES}

Berdnikova, O. A., \& Ivanov, S. E. (2015). Analysis and Dynamics of the Indicators of Tourism Development Using the Republic of Tatarstan as an Example. The Age of Quality, 1, 73-76.

Bunakov, O. A. (2016). Development of tourism in the region on the basis of cluster approach. International Business Management, 10(21), 5104-5106.

Bunakov, O. A., \& Rubtzov, V. A. (2016). Complexity of positioning in tourism as the basis of its sustainable development. International Business Management, 10(21), 5101-5103.

Eidelman, B. M., Bunakov, O. A., Nayda, A. M., Fakhrutdinova, L. R., \& Gabdrakhmanov, N. K. (2018). The analysis of world trends of territorial branding development. Journal of Social Sciences Research, 5, $306-309$.

Eidelman, B. M., Fakhrutdinova, L. R, \& Bunakov, O. A. (2018). The analysis of content of territorial brands of Kazan and the Republic of Tatarstan. Fournal of Social Sciences Research, 5, 448-453.

Kabirov, I. S. (2016). The Problems of Strategic Planning in Tourist Development Management of the Republic of Tatarstan. Azimuth of Scientific Studies: Economics and Management, 5(2(15)), 102-108.

Kalashnikova, S. V., \& Khanakhok, Z. A. (2015). The Tourism Draw of a Region as One of the Key Factors of its Competitive Position. New Technologies, 1, 3-8.

Neterin, A. V. (2018). Russia's Standing in the International Rating of the Tourism Attractiveness. Bulletin Science and Education, 1(7(43)), 69-71.

Niyaz, K., Gabdrakhmanov, N. K., Rubtzov, V. A., \& Biktimirov, N. M. (2018). Tourist and historical features of settlement on the territory of present tatarstan. Multidisciplinary Social Science \& Management, 2, 211-215. 
Tsurtsilina, A. Y. (2016). The Tourism Appeal as a Factor of Strategic Development of the Regions. Economy and Socium, 10(29), 12-17. 